\title{
Simulation Experiment to Predict the Critical Friction Area of Acetabular Liner Component on Hip Joint Replacement Implant During Movement
}

\author{
Tresna P. Soemardi ${ }^{1, *}$ Agri Suwandi ${ }^{2}$ Anwar Soefi Ibrahim ${ }^{3}$
}

\author{
${ }^{1}$ Departement of Mechanical Engineering, Universitas Indonesia, 16424, Indonesia \\ ${ }^{2}$ Departement of Mechanical Engineering, Universitas Pancasila, 12560, Indonesia \\ ${ }^{3}$ Department of Medical Physics, Universitas Indonesia, 10430, Indonesia \\ *Corresponding author. Email: tsoemardi@eng.ui.ac.id
}

\begin{abstract}
This paper has shown that simulation experiment to predict the critical friction area of acetabular liner component on hip joint replacement implant during movement. With the simulation method, that can help find the friction and stress area. The results of the friction simulation, the area friction of acetabular liner is $378,32 \mathrm{~mm} 2$ and $22,49 \mathrm{~mm} 2$ for the femoral head. Based on simulation stress analysis of acetabular liner shown the maximum value of von-Mises stress is $0.3994 \mathrm{MPa}$ and for the femoral head is $0.3411 \mathrm{MPa}$. From the simulation results, a map of the critical contact area is obtained, which is an important reference in the development of optimal designs for the acetabular liner and femoral head components.
\end{abstract}

Keywords: Simulation, Prediction, Friction, Hip Joint Replacement.

\section{INTRODUCTION}

The degenerative disease that frequently affects elderly patients is osteoarthritis that attacks the joints in different parts of the body; one of them is the hip joint. Complaints that occur can take the form of severe pain and often cause movement disorders and addiction to supports or help from others. One of the treatments given is surgery by replacing the hip joint with artificial materials that will permanently bond. The surgical procedure which removes the cartilage (see figure 1.a) and bones in the damaged hip joint (see Figure 1.b) and replaces them with artificial components is called a total hip joint replacement.

Hip joint replacement is currently one of the most performed procedures in orthopaedic practice in the United States. Since its introduction in this country in 1969, it has proven very successful in relieving pain and restoring hip function in diseases such as osteoarthritis (OA) [2]. Approximately 170,000 hip joint replacements are estimated to be performed annually in this country and about 300,000 worldwide. However, in Indonesia, the total hip joint replacement patient data published to date are only 216 patients from 2008-2017 (see figure 2) [3].

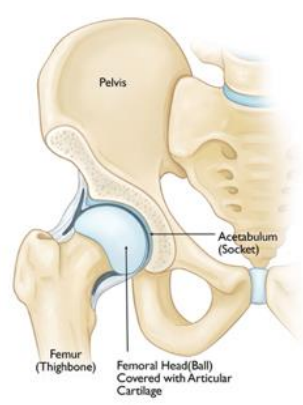

(a)

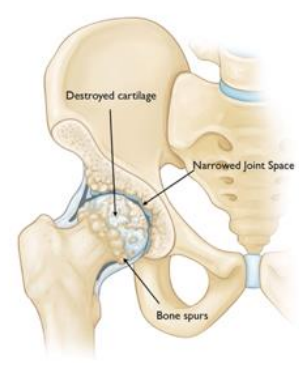

(b)
Figure 1 Osteoarthritis of the hip; (a). Parts of the hip; (b). Arthritis on the hip joint [1].

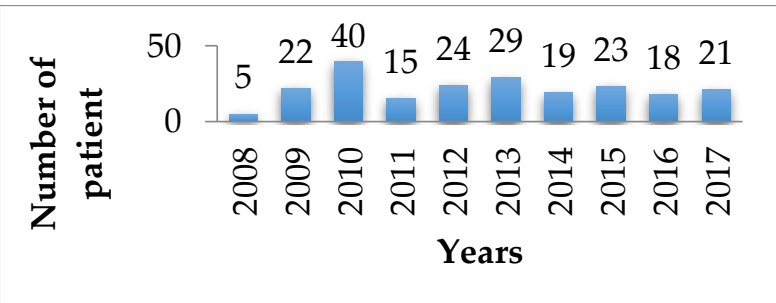

*the results of observation and data processing

Figure 2 The trend of hip replacement growth patients in Indonesia [3]. 
Even so, it seems that the number of patients treated is inadequate due to several reasons, among others, because of the high costs required to carry out the operation. The high price is due, among other things, to the expensive components for replacement joints and still must import from abroad. Besides, surgery can lead to further complications, including the appearance of tears on the surface of artificial joints, artificial joints that become loose and can even be separated, so repeated operations are frequently carried out to repair them [4]. The efforts made to overcome these advanced complications include the use of better materials. Also, striving for the fitting of joints between the parts to be more suitable, which in this case is often less than optimal because the available sizes are foreign standard sizes. Thus, making it more comfortable and safer to use [5].

There are four factors for the success of the total hip joint replacement implant surgery, that is, patient [6][7]; surgical technique [4]; implant design [8]; and implant manufacturing [9]. Implant design is the most critical factor and easy to perform optimization [8]. Compatibility of dimension [8], contact area [10] and material [11] are the three crucial points in implant design.

Based on references not showing the importance of component friction from sitting to standing position, this study aims to predict the friction area and stress of the acetabular liner and femoral head component during movement from sitting to standing. Critical contact during friction movement is one of the causes of implant damage. With the simulation will get a mapping critical contact area to do the development of the component design. The method used is an experiment using software to simulate friction and stress on the acetabular liner component design.

\section{METHOD}

Figure 3 as shown the steps in the research process. This study uses a simulation-based experimental method with Inventor and Ansys software. Total Hip Replacement (THR) design in this study is a customized product based on the geometry of the patient's hip bone. THR provides a comfortable fit and comfort to the implant users [12]. The geometric data obtained from the computed tomography (CT) results are two-dimensional images of the hip with osteoarthritis problems. The CT acquisition data converted into point cloud data to reconstructed into a 3D model. After obtaining the 3D hip model, the following step is to design the hip implant component based on the geometry that has obtained using the Inventor software.

THR is composed of four components; they are femoral stems, femoral head, acetabular liner and acetabular cup. For stress and friction simulation analysis in this study, only two components the femoral head and the acetabular liner. The femoral head made from stainless steel 316L (SS 316L) and the acetabular liner uses Ultra-High Molecular Weight Polyethylene (UHMWPE) material. Stress simulation analysis uses Inventor software, while for friction Ansys software is applied.

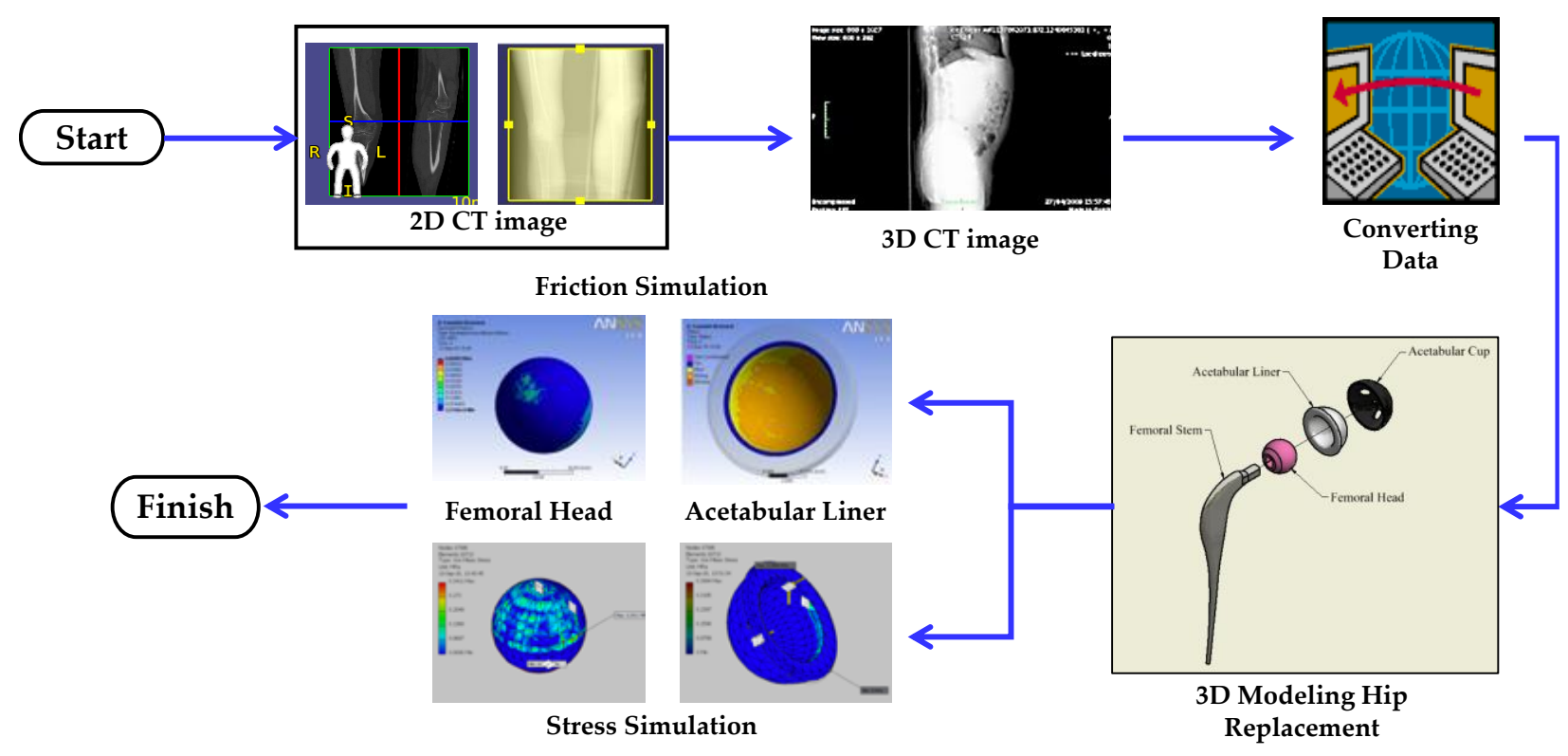

Figure 3 Steps of the simulation-based experimental method 


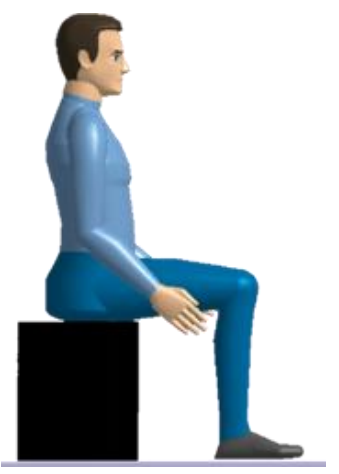

(a)

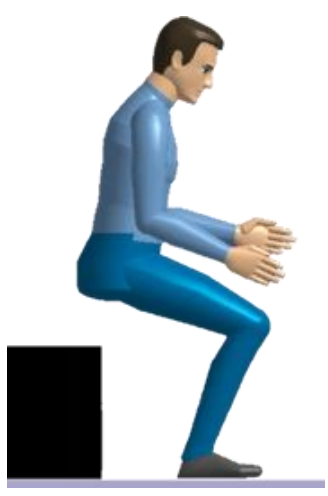

(b)

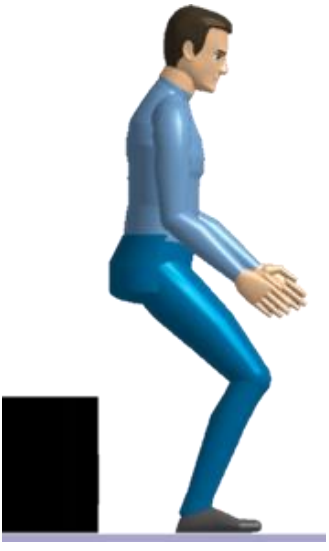

(c)

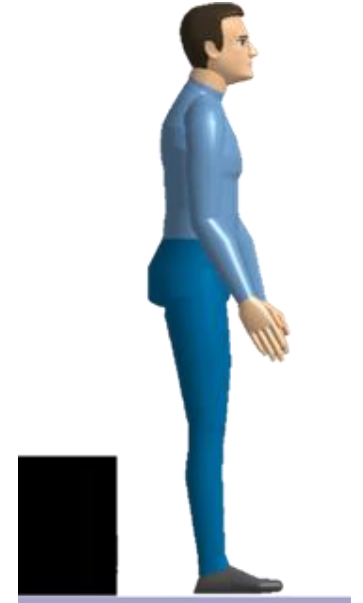

(d)

Figure 4 Motion illustration from sitting to standing; (a). Sitting; (b). Wake up; (c). Get up; (d). Standing

The friction and stress load parameters in the case study of the sitting to standing motion, as shown in Figure 4. Figure 4.a illustrated in the seating position, or the start point. Figure 4.b. shows the wake up position when the weight of the bearing with the highest value is distributed to the lower limb of the body weight [13][14]. Figure 4.c is get up position where the most significant impact moves to the ankle [13][14], while 4.d is standing position with the load on the lower limb [13]. Assuming the patient's body weight used is $70 \mathrm{~kg}$. Its, therefore, assumed that the body load distributed between the lower limb [13][14]. Based on this, the load carried by each hip is $35 \mathrm{~kg}$.

\section{RESULT AND DISCUSSION}

\subsection{Design of THR Components}

As shown in Figure 5, the component design obtained from the results of CT scan data which converted into cloud data in the image format. From these data, a reconstruction process carried out to get hip geometry data (see Figure 6).

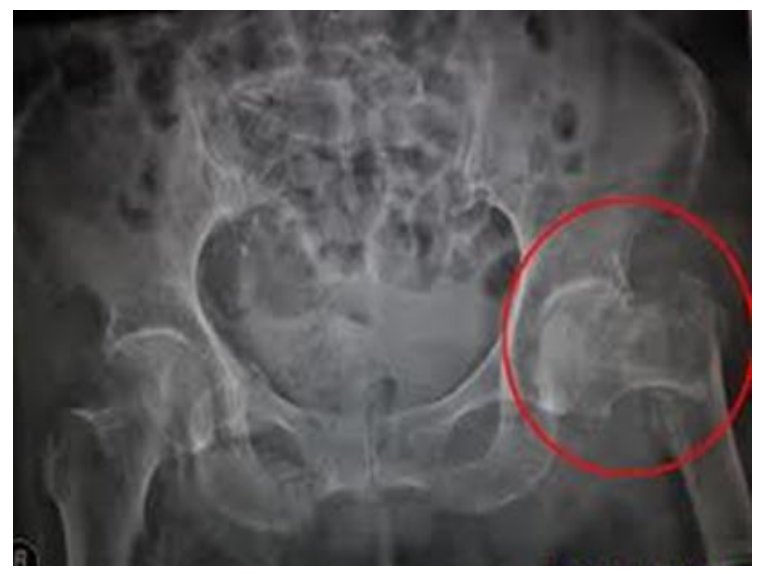

Figure 5 Image data hip from CT scan
After getting the geometry data, the next step is to design the THR components using the existing geometry with Inventor software. THR composed by femoral stems, femoral head, acetabular liner and acetabular cup (see Figure 7). After the THR design generates, then simulate friction and stress using the Ansys software. The linear and non-linear contact models are evaluated by their ability to match simulation experimental peak and average contact pressures simultaneously. Matching both is necessary for the predicted friction and stress distribution to match the experiments. Contact force comparisons are not reported since the force is always compared exactly at the final static configuration.

\subsection{Simulation of Friction and Stress Analysis}

The materials used are medical grade were SS $316 \mathrm{~L}$ for femoral head and UHMWPE for acetabular liner component. The mechanical properties of the materials categories can be seen in Table 1 .

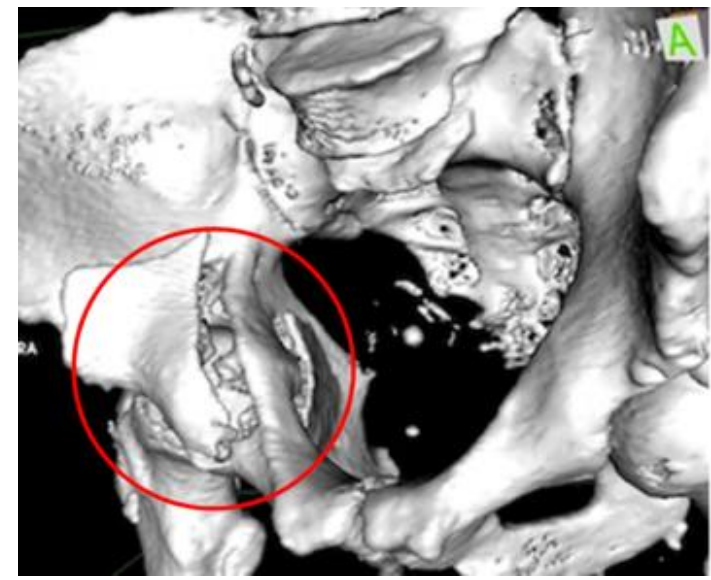

Figure 6 Reconstructions processes 


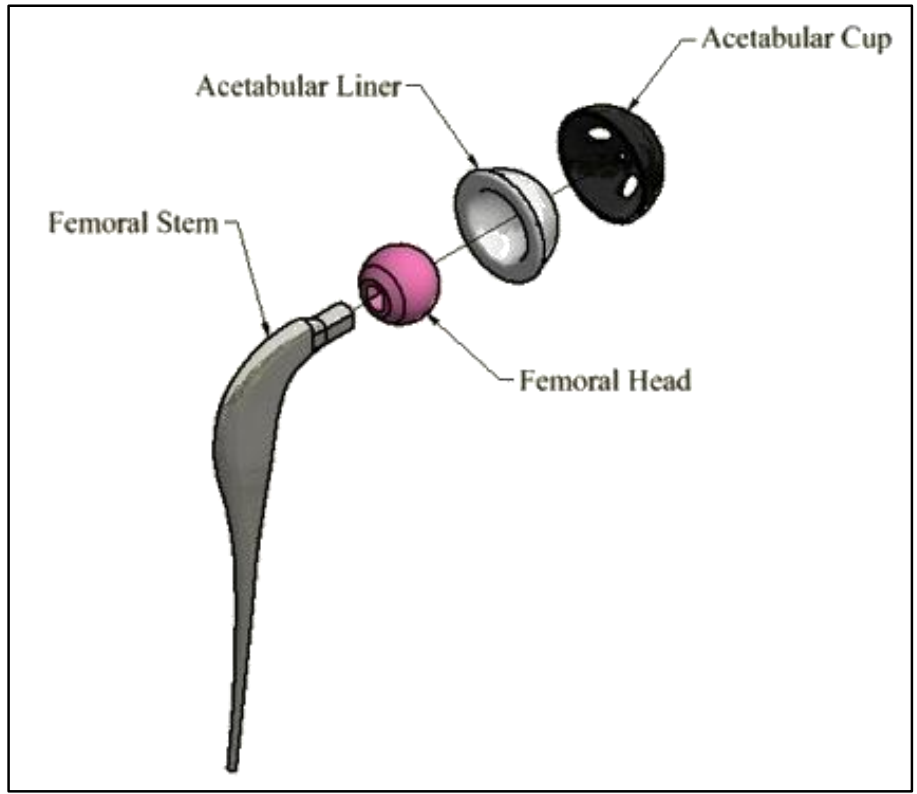

Figure 7 THR components

Table 1. Mechanical properties of material SS 316L and UHMWPE [15]

\begin{tabular}{lll}
\hline Properties & Materials & UHMWPE \\
\hline Ultimate Tensile Strength & SS 316L & $35 \mathrm{MPa}$ \\
Yield Strength & $515 \mathrm{MPa}$ & $20 \mathrm{MPa}$ \\
Young's Modulus & $205 \mathrm{MPa}$ & $0.760 \mathrm{GPa}$ \\
Poisson Ratio & $193 \mathrm{GPa}$ & $0,42 \mathrm{ul}$ \\
Standard tension test & $0.252 \mathrm{ul}$ & ASTM D638 - 14 \\
\hline
\end{tabular}

Based on Ansys simulation on figure 8, the friction of the acetabular liner on inner area has a $378,32 \mathrm{~mm}^{2}$ with 2.2145e-008 MPa Equivalent (von-Mises) Stress (see figure 8.a). Figure 8.b shown the results of the friction analysis for femoral head, the value of the total friction

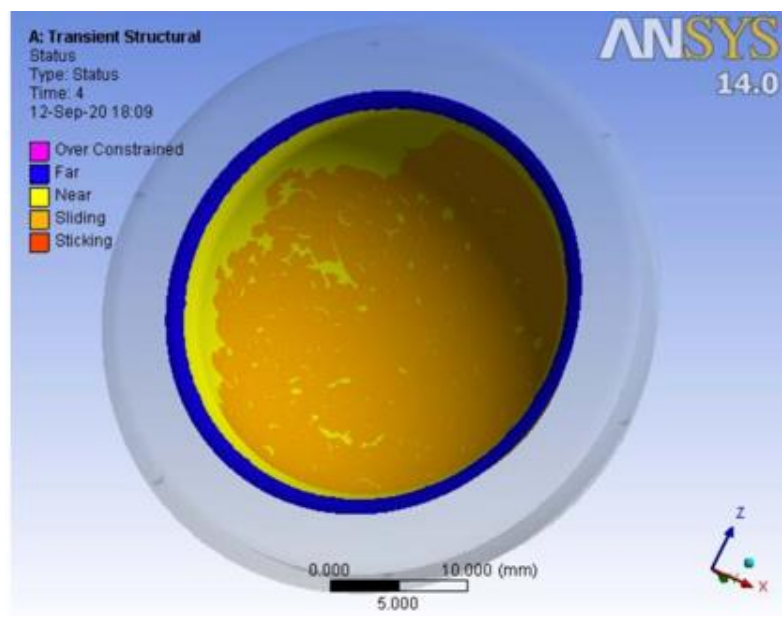

(a) area is 22,49 $\mathrm{mm}^{2}$ with $0.66963 \mathrm{MPa}$ for Equivalent (von-Mises) Stress. The visual analysis of femoral head (figure 8.b) shows the critical position is on top and side area where there is friction with the acetabular liner.

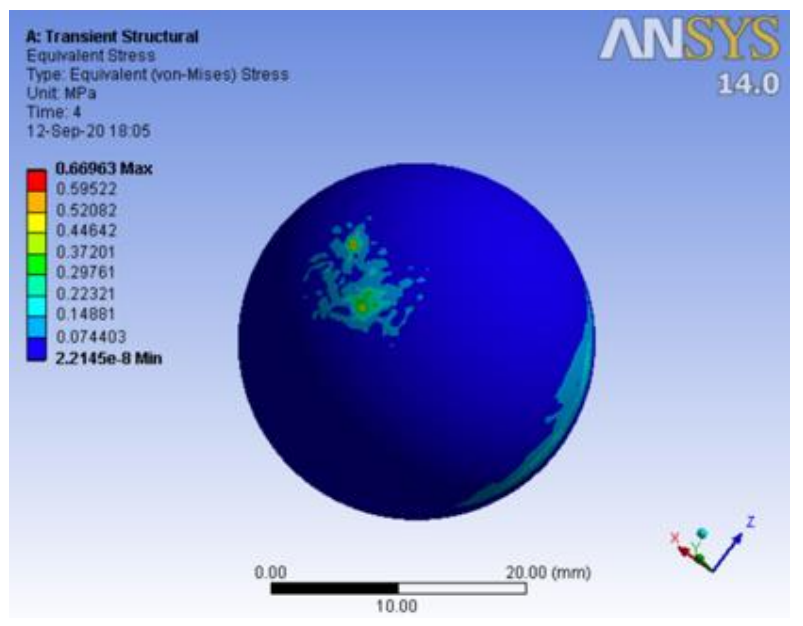

(b)

Figure 8 Friction analysis; (a). Acetabular Liner; (b). Femoral head 
Compared to the material characteristics of steel and polymer categories, the more excellent value of the vonMises of this material yield strength means that it is necessary to check the design model in the critical area [10][16][17]. For the Poisson ratio of the material is smaller than the Poisson ratio simulation analysis results (see on table 2); in other words, the level of safety exceeds the design of the material used [17][18].

In Figure 9.a, the maximum von-Mises stress value on the acetabular liner is $0.3994 \mathrm{MPa}$, while the Yield
Strength value of the UHMWPE material in table 1 (ASTM D638 - 14, Standard Test Method for Tensile Properties of Plastics) is $20 \mathrm{MPa}$. This condition shows that the acetabular liner design is safe. As for the femoral head, von-Mises stress the value of $0.3411 \mathrm{MPa}$ maximum value 316L SS material Yield Strength in table 1 (ASTM E 8/E 8M - 08, Standard Test Methods for Tension Testing of Metallic Materials) equal to $205 \mathrm{MPa}$; then the design stated is safe.

Table 2. Poisson ratio comparison between testing vs simulation result of material SS 316L and UHMWPE

\begin{tabular}{lll} 
Poisson ratio & Materials & UHMWPE \\
\hline Testing [15] & SS 316L & $0,42 \mathrm{ul}$ \\
Simulation & $0.252 \mathrm{ul}$ & $0.46 \mathrm{ul}$ \\
\hline
\end{tabular}

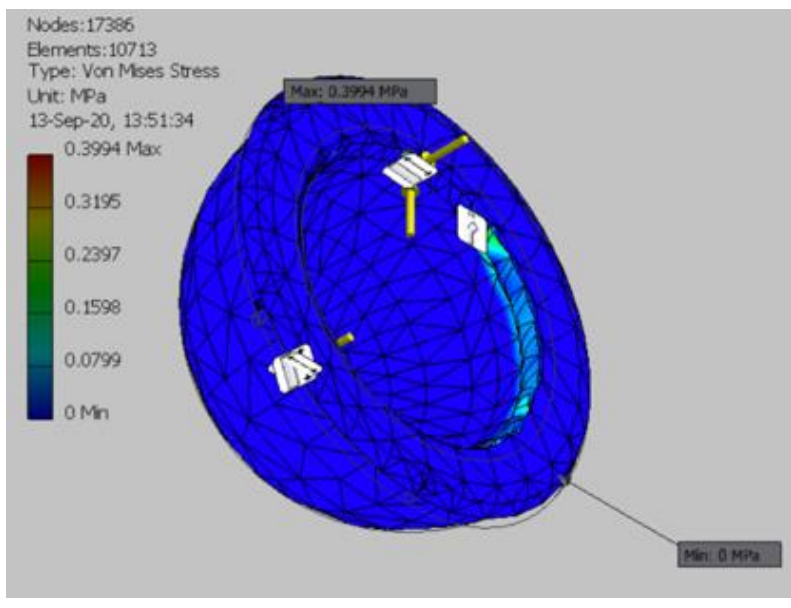

(a)

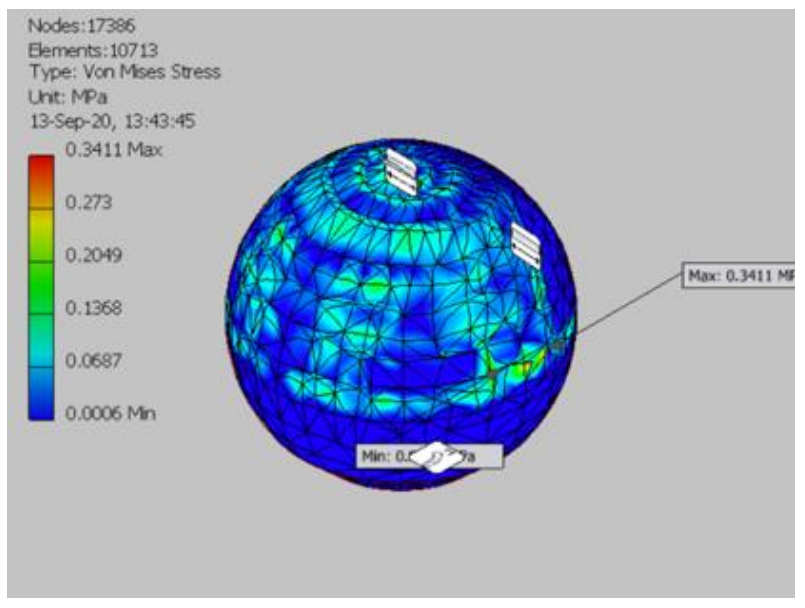

(b)

Figure 9 Stress analysis; (a). Acetabular Liner; (b). Femoral head

Stress analysis in Figure 9.a shows the location of the stress on the inner bottom side acetabular liner. This occurs at the bottom because there is pressure due to the simulated wake up position, as shown in Figure 4.b. Figure 9.b shows the pressure area on the femoral head component; in this figure, the pressure occurs in how many parts of the component. The maximum point of stress for the femoral head component is in the side in contact with the inner edge of the acetabular liner.

\section{CONCLUSION}

Based on simulation results, then obtained mapping of the critical contact from friction effect on the acetabular liner components during hip joint motion. The critical area is in the lower acetabular liner area, which is caused by the pressure of the femoral head on the standing position, where the weight of the body will lean towards the hip. The acetabular liner design is that the critical area requires more thickness than other areas so that the design is made thicker with $3-7 \mathrm{~mm}$ range of thickness based on ASTM F2033 - 20 for Standard Specification for Total Hip Joint Prosthesis [19]. Further research can be continued with the analysis of different movements.

\section{ACKNOWLEDGMENT}

The research grant has supported research, design, and development activities by the author mention in this paper "Penelitian Terapan Unggulan Perguruan Tinggi 2020", with contract number 8/AMD/E1/KP.PTNBH/2020 from the Ministry of Research Technology and Higher Education of the Republic of Indonesia and DRPM Universitas Indonesia with letters of agreement implementation research number NKB-359/UN2.RST/HKP.05.00/2020. The 
author also express thanks to Mr. Hindra Salim who advice for simulation motion and analysis.

\section{REFERENCES}

[1] C. G. Lawrence R.C.; Felson, D.T.; Helmick, "Osteoarthritis of the Hip," American Academy of Orthopaedic Surgeon (AAOS), 2016.

[2] I. N. Ackerman et al., "Lifetime Risk of Primary Total Hip Replacement Surgery for Osteoarthritis From 2003 to 2013: A Multinational Analysis Using National Registry Data," Arthritis Care Res., vol. 69, no. 11, pp. 1659-1667, Nov. 2017.

[3] R. Medistra, "Bedah Tulang: Total Knee Replacement Atasi Osteoarthritis," Medistra Hospital, 2017. [Online]. Available: http://www.medistra.com.

[4] E. A. Brembo, H. Kapstad, S. Van Dulmen, and H. Eide, "Role of self-efficacy and social support in short-term recovery after total hip replacement: A prospective cohort study," Health Qual. Life Outcomes, vol. 15, no. 1, Apr. 2017.

[5] A. Suwandi, G. Kiswanto, W. Kusumaningsih, and T. P. Soemardi, "Research - Design \&amp; Development of Fast Customized Manufacturing for Prostheses TKR Based on Rapid Prototyping," $A d v$. Mater. Res., vol. 980, pp. 243-247, Jun. 2014.

[6] S. Agarwala and S. C. M. Vijayvargiya, "Restoring Natural Hip Movements with Large Head (Ceramic on Ceramic) Total Hip Replacement: Experience of Our 150 Patients over 6 Years," J. Orthop., vol. 7, pp. 414-427, 2017.

[7] M. Wyatt, C. Frampton, and G. Hooper, "Is stem design important in uncemented total hip replacement to decrease subsidence in obese patients?," Ann. Jt., vol. 2, pp. 50-50, Aug. 2017.

[8] M. C. Sekhar, G. U. M. Rao, V. B. Neeharika, and K. Satyanarayana, "Design and Analysis of Artificial Hip Joint," Int. J. Eng. Manag. Res., vol. 7, no. 4, pp. 305-312, 2017.

[9] L. C. Zhang, E. C. S. Kiat, and A. Pramanik, "A Briefing on the Manufacture of Hip Joint Prostheses," in Advances in Abrasive Technology XII, 2009, vol. 76, pp. 212-216.

[10] A. Suwandi, T. P. Soemardi, G. Kiswanto, W. Kusumaningsih, and I. G. W. Gusti Agung,
"Development of friction and wear full-scale testing for TKR prostheses with reliable low cost apparatus," in AIP Conference Proceedings, 2018.

[11] M. Mitsuishi et al., "Biomanufacturing," CIRP Ann., vol. 62, no. 2, pp. 585-606, 2013.

[12] A. Suwandi, G. Kiswanto, W. Kusumaningsih, and T. P. Soemardi, "The accuracy of solid model and rapid prototype of prostheses in comparison to the digital CT image data," in AIP Conference Proceedings, 2017.

[13] T. W. Cacciatore, O. S. Mian, A. Peters, and B. L. Day, "Neuromechanical interference of posture on movement: evidence from Alexander Technique teachers rising from a chair," J. Neurophysiol., vol. 112, no. 3, pp. 719-729, 2014.

[14] T. Tsuji, K. Tsunoda, Y. Mitsuishi, and T. Okura, "Ground Reaction Force in Sit-to-stand Movement Reflects Lower Limb Muscle Strength and Power in Community-dwelling Older Adults," Int. J. Gerontol., vol. 9, no. 2, pp. 111-118, 2015.

[15] A. Suwandi, "Development of Fast Customized Prostheses Design \& Manufacturing for Total Knee Replacement," Universitas Indonesia, 2017.

[16] M. M. Ardestani, P. P. Amenábar Edwards, and M. A. Wimmer, "Prediction of Polyethylene Wear Rates from Gait Biomechanics and Implant Positioning in Total Hip Replacement," Clin. Orthop. Relat. Res., vol. 475, no. 8, pp. 2027-2042, Aug. 2017.

[17] A. Suwandi, D. Lia Zariatin, B. Sulaksono, E. Prayogi, and I. M. Widana, "Simulation-based Prediction of Structural Design Failure in Fishing Deck Machinery a Hydraulic Type with Finite Element Method," E3S Web Conf., vol. 130, 2019.

[18] A. Suwandi, T. P. Soemardi, G. Kiswanto, W. Kusumaningsih, and I. G. W. Gusti Agung, "Development of friction and wear full-scale testing for TKR prostheses with reliable low cost apparatus," in AIP Conference Proceedings, 2018, vol. 1933.

[19] ASTM International, “ASTM F2033-20, Standard Specification for Total Hip Joint Prosthesis and Hip Endoprosthesis Bearing Surfaces Made of Metallic, Ceramic, and Polymeric Materials." ASTM International, West Conshohocken, pp. 1-6, 2020. 